\title{
二维原子晶体: 新型的高效氢同位素分离滤膜
}

\author{
付 否 \\ (武汉大学化学与分子科学学院, 武汉 430072)
}

氢同位素对于现代分析方法和示踪技术非常 重要, 其重要化合物——重水更是作为减速剂被 广泛用于铀核裂变中。然而, 现有的氢同位素分 离技术, 如水-硫化氢交换和低温蒸馏法, 能耗极 大, 且分离效率很低(分离因子 $<2.5)^{1}$ 。因此, 发 展低能耗、高效的氢同位素分离技术是一项极具 挑战的工作。近期, 单原子层厚度的石墨烯和氮 化嗍为氢同位素的分离带来了突破, 它们作为仅 能通过热质子和电子的单层原子晶体, 在分离氢 同位素时表现出非凡的亚原子选择透过性。诺贝 尔物理学奖获得者 Geim 教授研究组 ${ }^{2}$ 以单层石墨 烯和氮化嗍这样一个极简的体系作为滤膜, 在室 温下成功分离了氢同位素, 且石墨烯滤膜的分离 因子高于 10。这项研究成果已在最新的 Science 上 发表。

在该项研究中, 他们采用了两种互补型方 法一一测量电导率和质谱检测气流, 探索了二维 原子晶体对気核 $\left(\mathrm{D}^{+}\right)$和氢核 $\left(\mathrm{H}^{+}\right)$的选择性。以后一 种方法为例, 他们通过输入一系列不同比例的 $\mathrm{H}^{+} 、 \mathrm{D}^{+}$混合溶液, 发现氢同位素均能透过石墨 烯, 但输出的氢原子分数与输入的 $\mathrm{H}^{+}$是不相称的 (如图 1b 所示), 由图 $1 \mathrm{~b}$ 计算分离因子约为 10 , 即 证实了石墨烯确实能高效地分离氢同位素。这种
高选择性其实是归因于同位素效应, 换言之, 即 二维原子晶体对氢核和氞核的传输能垒是不同 的。那么能垒差源自何处呢? 在该体系中, 在透 过二维原子晶体前, 氢核和氞核会与溶液里的基 团及水形成氢键 ${ }^{3}$, 而对于两者而言, 其氢氧键的 零点能是不同的, 两者表现出 $60 \mathrm{meV}$ 的能垒差。 因此, 可以推断如果质子传导介质具有更强的氢 键, 分离因子会更大, 则更有利于氢同位素的高 效分离。而且值得注意的是, 除了剥离法, 化学 气相沉积(CVD)法所制得的石墨烯和氮化硼同样在 篮离氢同位素方面表现出色, 他们基于此建立了 厘米级尺寸的设备, 并成功从氛和氢混合物中有 效地洜出了氢, 证明了此技术的可扩展性。

此项研究表明, 石墨烯及氮化硼对氢同位素 具有优异的选择性, 使得其能够有效分离氢同位 素。基于 CVD法制备的大面积石墨烯, 用简单的 篮分机制和分离设备, 并结合具有强的氢键的质 子传导介质, 未来科学家们有望实现氢同位素的 工业化分离。此外, 这种同位素分离法无需添加 其它化学物质, 能耗显著低于现有的分离富集过 程, 从而能有效地缓解能源和环境压力, 有望在 分析和化学示踪技术上发挥作用, 并真正地用于 核废料的处理上, 成为新一代超级 “过滤器”。
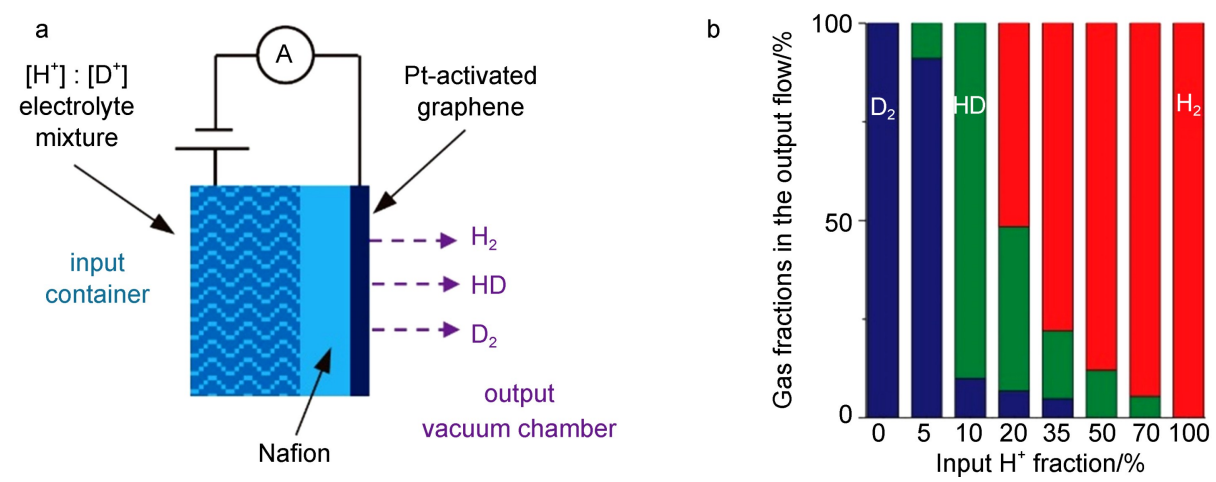

图 1 质谱检测气流法探测石墨烯对氢同位素的分离效果

(a) 质谱仪装置示意图; (b) 输出气流组分分布随输入 $\mathrm{H}^{+}$组分的变化关系图 


\section{References}

(1) Miller, A. I. Can. Nucl. Soc. Bull. 2001, 22 (1), 1.

(2) Lozada-Hidalgo, M.; Hu, S.; Marshall, O.; Mishchenko, A.; Grigorenko, A. N.; Dryfe, R. A. W.; Radha, B.; Grigorieva, I.
V.; Geim, A. K. Science 2016, 351 (6268), 68. doi: 10.1126/ science.aac9726

(3) Mauritz, K. A.; Moore, R. B. Chem. Rev. 2004, 104 (10), 4535. doi: $10.1021 / \mathrm{cr} 0207123$ 